\title{
Domates Güvesi Tuta absoluta (Meyrick) (Lepidoptera: Gelechiidae)'nın Bişkek popülasyonunun mitokondrial cytochrome oxidase subunit I (mtCOI)'e göre genetik özellikleri üzerine bir araştırma
}

\author{
A study on genetic trait of Bishkek population of Tuta absoluta (Meyrick) \\ (Lepidoptera: Gelechiidae) according to mitochondrial cytochrome oxidase subunit I \\ (mtCOI)
}

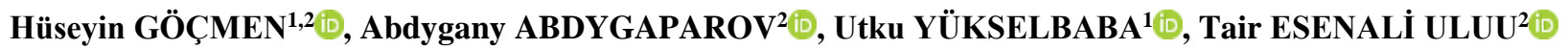 \\ ${ }^{1}$ Akdeniz Üniversitesi, Ziraat Fakültesi, Bitki Koruma Bölümü, Antalya, Türkiye \\ ${ }^{2}$ Kırgızistan Türkiye Manas Üniversitesi, Ziraat Fakültesi, Bitki Koruma Bölümü, Bişkek, Kırgızistan \\ Sorumlu yazar (Corresponding author): H. Göçmen, e-posta (e-mail): gocmen@akdeniz.edu.tr \\ Yazar(lar)e-posta (Author e-mail): abdyabdygaparov@gmail.com, uyukselbaba@akdeniz.edu.tr, tair2992@gmail.com
}

MAKALE BİLGİSİ

Alınış tarihi 27 Mart 2019

Düzeltilme tarihi 30 Nisan 2019

Kabul tarihi 02 Mayıs 2019

\section{Anahtar Kelimeler:}

Tuta absoluta

miCOI

Kirgizistan

\begin{abstract}
ÖZ
Bu çalışmada Kırgızistan'da ilk kez 2017 yılında Bişkek’te tespit edilen Tuta absoluta'nın mitokondrial cytochrome oxidase subunit I(mtCOI) gen bölgesinin sekansına göre genetik özelliklerinin ortaya konulması amaçlanmıştır. Çalışmada Bişkek'ten toplanan Domates güvesi bireylerinden DNA izolasyonu yapılmış ve takiben mtCOI bölgesi spesifik primerler ile amplifiye edilerek sekansı yapılmıștır. Elde edilen sekans dizileri GenBank’tan alınan 22 domates güvesi sekans verileri ile karşılaştırılarak filogenetik ağaç oluşturulmuştur. Analiz sonucunda Kırgızistan örneği ile GenBank verilerinin yüksek benzerlik gösterdiği görülmüştür. Sekans verileri ileriki çalışmalarda kullanılmak üzere GenBank'a kayıt ettirilmiştir. Farklı moleküler markirlar ile Kırgızistan'ın diğer bölgelerinden de toplanacak $T$. absoluta örnekleri üzerinde yapılacak araștırmalar, zararlının genetik çeșitliliğine, orijinine ve ileride yapılacak çalışmalara 1 şık tutabilecektir.
\end{abstract}

\section{ARTICLE INFO}

Received 27 March 2019

Received in revised form 30 April 2019

Accepted 02 May 2019

Keywords:

Tuta absoluta

mtCOI

Kyrgyzstan

\begin{abstract}
In this study determination of the genetic trait of Tuta absoluta which was first determine in Kyrgyzstan in 2017, according to the sequence of mitochondrial cytochrome oxidase subunit I (mtCOI) gene region was aimed. In the study, DNA isolation was made from the tomato borer individuals collected from Bishkek and then the mtCOI region was amplified with specific primers and sequenced. The sequence data were compared with twenty-two tomato borer sequence data from GenBank and then phylogenetic tree were constructed. As a result of the analysis, it is seen that Kyrgyzstan sample showed high similarity with those GenBank data. Sequence data of Bishkek population were submitted to Genbank for futher studies. Research on the genetic diversity of T. absoluta samples collected from other regions Kyrgyzstan is thought to be beneficial for integrated pest management. Researches on T. absoluta samples collected from different regions of Kyrgyzstan with different molecular markers will be able to shed light on the genetic diversity, origin and future studies of the pest.
\end{abstract}

\section{Giriş}

Domates güvesi, Tuta absoluta (Meyrick) Güney Amerika orijinli bir zararlı olup, bulaşmış olduğu yerlerde domates üretiminin en önemli zararlılarının başında gelmektedir. Clarke (1962) tarafindan Japonya'dan bildirilmesine rağmen zararlı Peru orijinlidir ve Güney Amerika'nın neredeyse tamamında yayılmış durumdadır. Zararlı, Avrupa'da ilk olarak 2006 yılında İspanya da görülmüş ve başta İtalya, Fransa, Portekiz, Almanya, Hollanda, İngiltere, Yunanistan, olmak üzere zamanla
Avrupa kıtasına yayılmıştır (Urbaneja ve ark. 2007; Garzia 2009; Korycinska ve Moran 2009). Afrika kıtasında 2008 y1lında tespit edilen (Anonim 2019) domates güvesi 2009 yılında Türkiye'de (Kılıç 2010), 2010-2011 yıllarında da Irak, Suriye, Suudi Arabistan, Lübnan, Ürdün, Filistin ve İsrail'de saptanmıştır (USDA 2011; Öztemiz 2012). Kırgızistan'da ise ilk kez 2017 yılında Bişkek’te tespit edilmiştir (Uulu ve ark. 2017). 
Yüksek üreme gücü ve zarar potansiyeline sahip domates güvesi ile ilgili olarak günümüze kadar zararlının popülasyon dalgalanması, bulaşma durumu, mücadelesi ve genetik çeşitliliği ile ilgili çeşitli çalışmalar yapılmıştır (Bayram ve ark. 2014; Portakaldalı ve ark. 2014; Tatlı ve Göçmen 2011; Asma ve Kaouthar 2017). Kirgizistan'da ise T. absoluta ile ilgili Uulu ve ark. (2017) tarafindan ilk rapor dışında herhangi bir çalışma bulunmamaktadır.

Domates güvesi gibi istilacı bir türün geniş bir coğrafi alana yayılma başarısı, adaptasyonunu destekleyen hem biyotik hem de abiyotik faktörlerle belirlenebilmektedir (Cifuentes ve ark. 2011). Bu faktörleri belirlemeye yönelik çalışmalar istilacı türlerle ilgili bilgileri geliştirmek ve onların mücadeleleri için kullanışlı olabilmektedir. Bununla birlikte, tüm bu faktörlerin yeterli bir şekilde anlaşılması, istilacı türlerin popülasyonları arasındaki filogenetik ilişkilerin yanı sıra, başarılı bir istilaya neden olan özelliklerin veya genetik özelliklerin temelini bilmeyi gerektirmektedir. İlave olarak istilac1 bir popülasyonunun genetik yapısını ve çeşitliliğini moleküler markerler kullanarak yerli popülasyonlarla kıyaslama, gen akışını, göç oranlarını, popülasyonlar arasındaki izolasyonu ve genetik farklılaşma ile ilgili diğer mikro-evrimsel süreçleri anlamada yardımcı olmaktadır (Hufbauer ve Roderick 2005; Ito ve ark. 2011; Shashank ve ark. 2018). Domates güvesi ile ilgili farklı araştırmacılar tarafından yapılmış genetik çalışmalar bulunmaktadır. Yükselbaba ve Göçmen (2017) Gelechiidae familyasına ait üç tür T. absoluta, Phthorimaea operculella (Zeller) ve Pectinophora gossypiella (Saunders)'nın genetik varyasyonunu mtCOI gen bölgesine göre çalışmışlardır. Cifuentes ve ark. (2011) 23 Akdeniz ve 10 Kuzey Amerika popülasyonunun genetik yapısını mtCOI ve ITS bölgelerine göre analiz etmişlerdir. Shashank ve ark (2018) ise $T$. absoluta'nın beş Hindistan ve bir Nepal popülasyonunun genetik çeşitliliğini mtCOI bölgesine göre çalışmışlar ve ekonomik zarar ve yayılma potansiyeli göz önüne alındığında, zararlının istilasının izlenmesinin kritik olduğunu ve bir popülasyonun yeni ülkeye giriş kaynağının bilinmesinin çok önemli olduğunu bildirmişlerdir.

$\mathrm{Bu}$ çalışmada Kırgızistan için yeni bir tür olan $T$. absoluta'nın mitochondrial cytochrome oxidase subunit I gen bölgesinin sekansına dayanarak DNA etiketlemesi ve filogenetik analizininin yapılması amaçlanmıştır.

\section{Materyal ve Yöntem}

Tuta absoluta ergin ve larva dönemine ait örnekler Bişkek ili yakınlarındaki domates üretimi yapılan seralarda feromon tuzaklarından ve domates bitkileri üzerinden toplanmıştır.

\subsection{DNA İzolasyonu ve mtCOI reaksiyonlart}

Çalışmada DNA izolasyonları tek bir bireyden yapılmış ve her biyolojik dönemden 10 birey alınarak ayrı ayrı DNA izolasyonları yapılmıştır. Domates güvesi DNA izolasyonları EZNA SQ Tissue DNA kit protokolü dikkate alınarak Yükselbaba ve Göçmen (2016) tarafindan belirtildiği gibi yapılmıştır. DNA izolasyonunu takiben mtCOI bölgesi "C1-J21955 'TTG ATT TTTTGGTCA TCC AGA AGT 3' ve TL2N-3014 5'TCC AAT GCA CTA ATC TGC CATATT A 3’" primerleri (Simon ve ark. 1994) kullanılarak polimeraz zincir reaksiyonu (PCR) ile çoğaltılmıştır. PCR reaksiyonları Yükselbaba ve Göçmen (2016)'in çalışmalarındaki gibi bazı bileșenlerin miktarları, süre ve derece modifiye edilerek toplam $12.5 \mu \mathrm{l}$ hacimde $0.5 \mu \mathrm{l}$ kalı DNA, $0.08 \mu \mathrm{l}$ Taq DNA polymerase ( 5 unit $\left.\mu \mathrm{l}^{-1}\right), 0.3 \mu \mathrm{l}$ her bir primerden $(0.2 \mu \mathrm{M}), 0.3$ $\mu l 10 \mathrm{mM}$ DNTPs, $1.2 \mu \mathrm{l}$ taq buffer, $1 \mu 125 \mathrm{mM} \mathrm{MgCl}_{2}$ ve 8.82 $\mu \mathrm{l}$ olacak şekilde, $4 \mathrm{dk} 94^{\circ} \mathrm{C}$ 'de, takiben 35 döngü [50 sn $94^{\circ} \mathrm{C}$ 'de, 45 sn $50^{\circ} \mathrm{C}$ 'de ve 50 sn $\left.72^{\circ} \mathrm{C}^{\prime} \mathrm{de}\right]$ ve son olarak $4 \mathrm{dk}$ $72^{\circ} \mathrm{C}$ PCR şartlarında gerçekleştirilmiştir.

PCR ürünleri \%0.8'lik TAE Agorose jelde görüntülenmiştir. Sekans dizi analizi iki yönlü olarak BM labosis (AnkaraTürkiye) firması tarafından yapılmış, elde edilen diziler aynı zamanda manuel olarak da kontrol edilmiştir. Sekans dizilimi NCBI GenBank veri tabanında BLAST analizine tabi tutulmuştur. Daha sonra bir örneğin sekans dizilimi GenBank veri tabanına Kırgızistan örneği olarak MK639787 kayıt numarası ile eklenmiştir (http://www.ncbi.nlm.nih.gov).

Kırgızistan popülasyonuna ait örnek ve GenBank veri tabanından BLAST analizi sonucunda homoloji gösteren $T$. absoluta dizilimleri ClustalX programı kullanılarak çoklu dizi hizalama analize tabi tutulmuştur. Filogenetik analizler PHYLIP paket programı kullanılarak distance matrix'e göre yapılmıştır. Filogenetik ağaç evolutionary distance verisi ile Kimura twoparamater model kullanılarak Neigbor-joining methoda göre 1000 Bootstarp tekrarlı olarak yeniden oluşturulmuştur (Felsenstein 1993). Phthorimaea operculella outgroup (D1ş grup) olarak kullanılmıştır.

\section{Bulgular ve Tartışma}

Tuta absoluta'nın DNA izolasyonu sonucunda mtCOI bölgesi Thermocycler'da çoğaltılmış ve yaklaşı 850 bp'lik PCR ürünü elde edilmiştir. Elde edilen PCR ürünlerinin çift yönlü sekans analizlerinin nükleotit dizilimleri hem forward hemde reverse sonuçlarına göre manuel olarak düzeltilmiş ve 849 bp'lik dizilim GenBank'a MK639787 kod ile kayıt ettirilmiştir. Blast analizi sonucunda elde edilen sekans diziliminin $T$. absoluta ile yüksek homoloji gösterdiği belirlenmiştir. NCBI GenBank’tan Blast analizi sonucuna göre indirilen 22 sekans verisi ile dizi doğrulama analizi yapılmış ve yapılan dizi doğrulama analizi sonuçları 611 konservatif bölge, 57 değişken, 2 parsim-bilgi ve 55 singleton bölge içerdiğ bilgisini vermiştir.

Neighbor-joining filogenetik ağaç toplam 23 sekans dizilimi kullanılarak 1000 bootstrap tekrarı ile oluşturulmuştur (Şekil 1). Buna göre Kırgızistan örneğinin sekans dizilimi Peru (HQ873064) ve İspanya (HQ873069) örneği ile alt kümeleşme göstermiştir (Şekil 1). Coğrafi olarak birbirinden farklı ülkeler ile alt kümeleşme göstermesi $T$. absoluta popülasyonları arasında mtCOI bölgesine göre yüksek homojenlik olduğunu göstermektedir. Domates güvesi popülasyonları arasında mtCOI bölgesi sekans verilerine göre yüksek homojenlik olduğu farklı çalışmalarda da bildirilmiştir. Shashank ve ark. (2018) yaptıkları çalışmada Hindistan ve Nepal'dan topladıkları örnekleri ve NCBI veri tabanından elde ettikleri toplamda 40 örneği mtCOI bölgesi sekanslarına göre kıyaslamışlardır. Çalışmaları neticesinde oluşturdukları filogenetik ağaçta coğrafik orijin ile ilişkili kümeleşme olmadığını belirtmişler ve coğrafik kümeleşme olmamasının nedeninin $T$. absoluta popülasyonlarının homojenlik göstermesi olduğunu bildirmişlerdir. Yükselbaba ve Göçmen (2016) Türkiye Batı Akdeniz bölgesi T. absoluta popülasyonlarının mtCOI bölgesine göre genetik varyasyonunu inceledikleri çalışmalarında popülasyonlar arasında ve popülasyon içinde yüksek homojenlik olduğunu ve Türkiye popülasyonlarının Güney Amerika ve bazı Avrupa popülasyonları ile yüksek benzerlik gösterdiklerini bildirmişlerdir. Benzer bir çalışma 


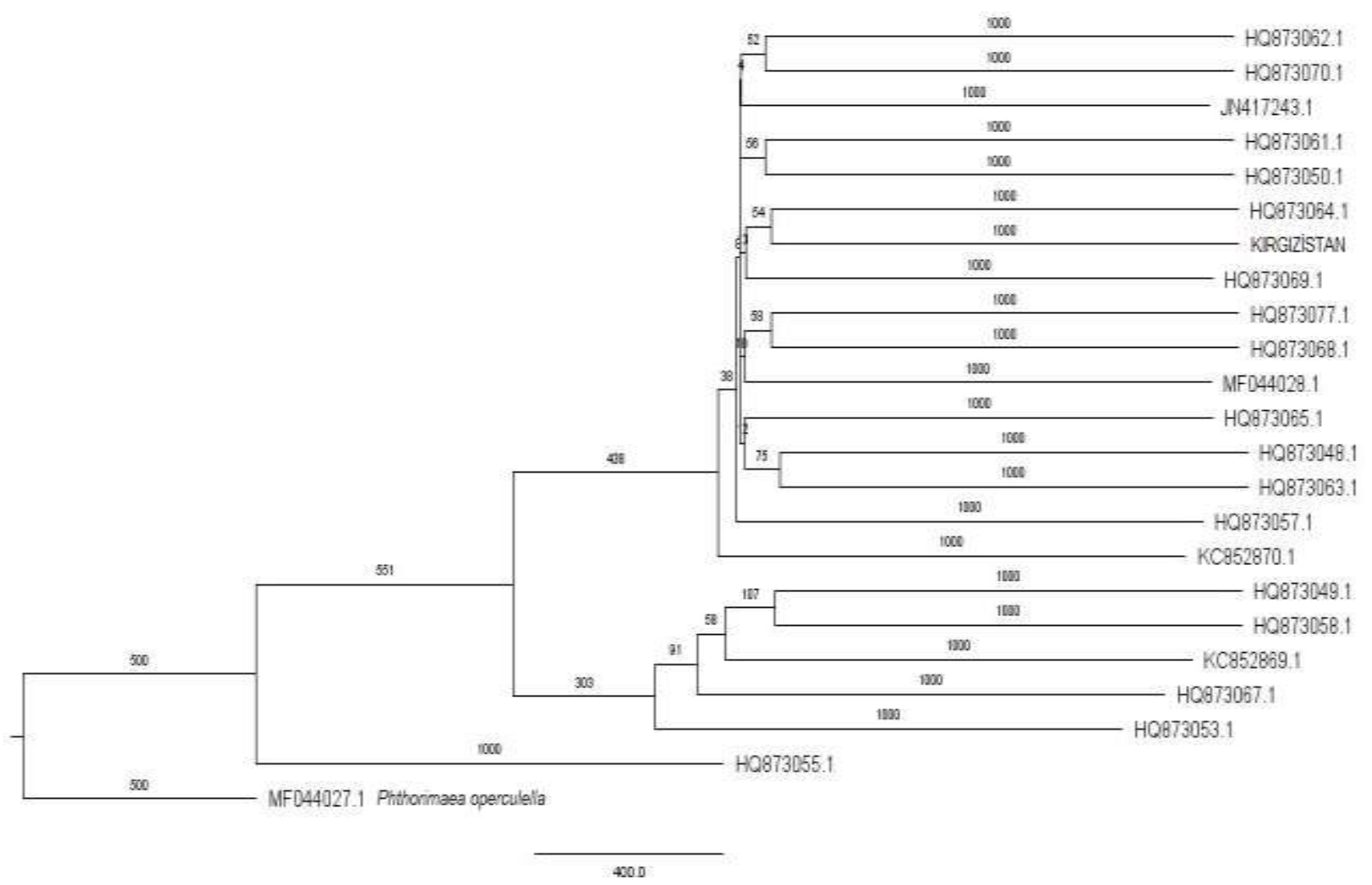

Şekil 1. Tuta absoluta populasyonlarının 1000 bootstrap tekrarlı ve two-parameter model ile neigbour joining filogenetik ağacı.

Figure 1. Neigbour joining Phylogenetic tree of Tuta absoluta populations based on Kimura two-parameter model with 1000 bootstrap replicates.

23 Akdeniz ve 10 Güney Amerika T. absoluta popülasyolarının genetik çeşitliliği mtCOI ve internal transcribed spacers 1 (ITS1) gen bölgesine göre Cifuentes ve ark. (2011) tarafindan çalışılmıştır. Araştırıcılar, Akdeniz ve Güney Amerika $T$. absoluta popülasyonlarında yüksek genetik homojenlik gözlemlemişler ve tek tip genetik yapı olduğunu bildirmişlerdir. Benzer şekilde Duric ve ark. (2014) Bosna-Hersek ve Karadağ popülasyonlarınının ve çalışmalarında kullandıkları popülasyonların mtCOI sekans dizilimlerinin kıyaslanması ile yüksek benzerlik gösterdiğini bildirmişlerdir. mtCOI bölgesine göre popülasyonlar arasında belirlenen yüksek homojenliğin aksine farklı moleküler markırlar kullanılarak yapılan çalışmalarda domates güvesi popülasyonları arasında genetik varyasyon bildirilmiştir (Suinaga ve ark. 2004; Bettaibi ve ark. 2012; Guillemaud ve ark. 2015).

\section{Sonuç}

Sonuç olarak, T. absoluta ülkeler arasında çok hızla yayılmakta ve farklı iklim koşullarına adapte olabilmektedir. Bu çalışma ile yüksek üreme gücü ve yayllım kabiliyetine sahip istilacı tür T. absoluta' nın mtCOI bölgesinin sekansına göre tanımlanması ve filogenetik analizi Kırgızistan'da ilk kez yapılmıştır.

Moleküler çalışmalarda mitokondriyal DNA, genetik çeşitlilik, istilacı türlerin teşhisi ve orijinlerini belirlemek üzere kullanılmaktadır. Ancak çalışmamızda ve diğer çalışmalarda domates güvesi popülasyonları arasında yüksek homojenlik olması, mtCOI'nin T. absoluta'nın Kırgızistan'a girişini açıklamada yetersiz kalmaktadır. Farklı moleküler marker sistemleri kullanılarak zararlının popülasyonları arasında genetik çeşitlilik belirlenebilmektedir. Zararlı üzerine Kırgızistan'ın diğer bölgelerinden de örnekler toplanarak ve farklı moleküler yöntemler kullanılarak yapılacak çalışmaların zararlının genetik çeşitliliğine, orijinine ve ileride yapılacak çalışmalara 1şık tutabilecektir.

\section{Kaynaklar}

Anonim (2019) CABI https://www.cabi.org/isc/datasheet/49260. Erişim 20 Şubat 2019.

Asma C, Kaouthar LG (2017) Population dynamics of the tomato leaf miner Tuta absoluta (Meyrick) (Lepidoptera: Gelechiidae) in Tunisia natural conditions Journal of Entomology and Zoology Studies 5(4): 427-432.

Bayram Y, Bektaş Ö, Büyük M, Bayram N, Duman M, Mutlu Ç (2014) Güneydoğu Anadolu Bölgesi'nde domates güvesi [(Tuta absoluta Meyrick) (Lepidoptera: Gelechiidae)] ve doğal düşmanlarının sürveyi Türkiye Biyolajik Mücadele Dergisi. 5(2): 99-110.

Bettaibi A, Mezghani-Khemakhem M, Bouktila D, Makni H, Makni M (2012) Genetic Variability of the tomato leaf miner (Tuta absoluta Meyrick; Lepidoptera: Gelechiidae), in Tunisia, inferred from RAPD-PCR. Chilean Journal of Agricultural Research 72(2): 212216.

Cifuentes D, Chynoweth R, Bielza P (2011) Genetic study of Mediterranean and South American populations of tomato leafminer Tuta absoluta (Povolny, 1994) (Lepidoptera: Gelechiidae) using ribosomal and mitochondrial markers. Pest Management Science 67(9): 1155-1162.

Clarke JFG (1962) New species of microlepidoptera from Japan. Entomological News, 73. 
Duric Z, Delic D, Hrncic S, Radonjic S (2014) Distribution and molecular identification of Tuta absoluta (Meyrick, 1917) (Lepidoptera, Gelechiidae) populations in Bosnia and Herzegovina and Montenegro. Polish journal of Entomology 83: 121-129.

Felsenstein J (1993) PHYLIP (Phylogeny Inference Package) version 3.5c. Distributed by the author. Department of Genetics, University of Washington, Seattle.

Garzia GT (2009) Physalis peruviana L. (Solanaceae), A Host Plant of Tuta absoluta in Italy. IOBC/WPRS Bull. 49: 231-232.

Guillemaud T, Blin A, Le Goff I, Desneux N, Reyes M, Tabone E, Tsagkarakou A, Nino L, Lambert E (2015) The tomato borer, Tuta absoluta invading the Mediterranean Basin, originates from a single introduction from Central Chile. Scientific reports. doi: $10.1038 /$ srep08371.

Hufbauer RA, Roderick GK (2005) Microevolution in biological control: mechanisms, patterns, and processes. Biol Control 35: 227 239.

Ito K, Nishikawa H, Shimada T, Ogawa K, Minamiya Y, Tomoda M, Nakahira K, Kodama R, Fukuda T, Arakawa R (2011) Analysis of genetic variation and phylogeny of the predatory bug, Pilophorus typicus, in Japan using mitochondrial gene sequences. J Insect Sci. 11: 18.

Kılıç T (2010) First record of Tuta absoluta in Turkey. Phytoparasitica 38(3): 243-244.

Korycinska A, Moran H (2009) Plant Pest Notice: South American Tomato Moth, Tuta absoluta (No. 56). Department for Environment, Food and Rural Affairs, Food and Environment Research Agency (Fera). pp. 1-4.

Öztemiz S (2012) Domates güvesi [(Tuta absoluta Meyrick (Lepidoptera: Gelechiidae)] ve Biyolojik Mücadelesi. KSÜ Doğa Bilimleri Dergisi 15(4): 47-57.

Portakaldalı M, Öztemiz S, Halil Kütük H,Hasan Deda Büyüköztürk HD (2014) Adana'da Açık Alan Domates Yetiştiriciliğinde Tuta absoluta (Meyrick) (Lepidoptera: Gelechiidae) ve Doğal Düşmanlarının Populasyon Dalgalanması. Türkiye V. Bitki Koruma Kongresi, Antalya, s. 73.
Shashank PR, Twinkle S, Chandrashekar K, Meshram NM, Suroshe SS, Bajracharya ASR (2018) Genetic homogeneity in South American tomato pinworm, Tuta absoluta: a new invasive pest to oriental region. 3 Biotech 8(8): 350-357.

Simon C, Frati F, Bechenbach A, Crespi B, Liu H, Flook P (1994) Evolution, weighting, and phylogenetic utility of mitochondrial gene sequence and compilation of conserved polymerase chain reaction primers. Annals of the Entomological Society of America 87: 651-701.

Suinaga FA, Casali VWD, Picanço M, Foster J (2004) Genetic divergence among tomato leafminer populations based on AFLP analysis. Pesq. Agropec. Bras. 39(7): 645-651.

Tatlı E, Göçmen H (2011) Domates Güvesi, Tuta absoluta (Meyrick) (Lepidoptera: Gelechiidae)' nın Batı Akdeniz Bölgesi Domates Üretim Alanlarında Yayılışının ve Populasyon Değişiminin İzlenmesi. Türkiye IV. Bitki Koruma Kongresi Bildirileri 28-30 Haziran 2011, Kahramanmaraş s. 271.

Urbaneja A, Vercher R, Navarro V, García Marí F, Porcuna JL (2007) La polilla del tomate, Tuta absoluta. Phytoma-Espana 194: 16-23.

USDA (2011) Federal Import Quarantine Order for Host Materials of Tomato Leafminer, Tuta absoluta (Meyrick). SPRO\# DA-2011-12. United States Department of Agriculture, Plant Protection and Quarantine. http://www.aphis.usda.gov.

Uulu TE, Ulusoy M, Çalișkan AF (2017) First record of tomato leafminer Tuta absoluta Meyrick (Lepidoptera: Gelechiidae) in Kyrgyzstan. EPPO Bulletin 47: 285-287.

Yükselbaba U, Göçmen H (2016) Domates güvesinin [Tuta absoluta (Meyrick) (Lepidoptera: Gelechiidae)] Batı Akdeniz Bölgesi populasyonlarının mitokondrial cytochrome oxidase subunit I (mtCOI)'e göre genetik varyasyonunun incelenmesi Mediterreanean Agricultural Sciences 29(1): 5-7.

Yükselbaba U, Göçmen H (2017) Molecular Identification of Three Gelechiidae Species Based on The Mitochondrial cytochrome Oxidase Gene I (MtCOI) Sequences. The Eurasian Agriculture and Natural Sciences Congress, Bishkek, Kyrgyzstan, pp. 123. 